$\mathbb{T}$ periodica polytechnica

Civil Engineering

$52 / 2(2008) 73+82$

doi: 10.3311/pp.ci.2008-2.03

web: http://www.pp.bme.hu/ci

(c) Periodica Polytechnica 2008

RESEARCH ARTICLE

\section{Investigation on load bearing capacity of glass panes}

Kinga Pankhardt

Received 2008-06-04, revised 2008-07-24, accepted 2008-10-21

\begin{abstract}
An experimental study was carried out on BME Department of Construction Materials and Engineering Geology to analyse the bending strength of glass pane. The influence of edge strength of single ply and laminated glass specimens were also investigated. Non heat treated and tempered single ply glass specimens of different thicknesses $6 \mathrm{~mm}, 12 \mathrm{~mm}$ and $19 \mathrm{~mm}$ and laminated $(2 \times 6 \mathrm{~mm}, 3 \times 6 \mathrm{~mm})$ glass specimens with constant span of $1.0 \mathrm{~m}$ and width of $0.36 \mathrm{~m}$ were tested in a four-point bending according to EN 1288-3:2000 [1]. The effect of interlayer material (resin and EVA foil) and the effect of temperature $\left(-20^{\circ} \mathrm{C},+23^{\circ} \mathrm{C},+60^{\circ} \mathrm{C}\right)$ on the structural behaviour of glass products were also studied. Strains were measured with strain gages in two regions of the surface of the glass pane (Region1 and Region2), see Fig. 1

Surface stresses in two regions and bending strength of glass specimens were determined.
\end{abstract}

\section{Keywords}

glass · tempered glass - surface stress · strain · bending strength $\cdot$ interlayer $\cdot$ temperature

\section{Acknowledgement}

The author expresses her gratitude to BME Department of Construction Materials and Engineering Geology, Prof. György L. BALÁZS and to RÁKOSY Glass Ltd. for providing the specimens and Dr. Salem G. NEHME for his intellectual and Mr. Sándor FEHÉRVÁRI for the technical support.

\section{Kinga Pankhardt}

Department of Civil Engineering, Debrecen University, H-4028 Debrecen, Hungary

e-mail: kpankhardt@yahoo.com

\section{Introduction}

Where would buildings be without windows? Glass is everywhere in modern life (lighting, household wares, cars, glass fibers etc.). Nowadays in architecture glass is used not only in windows but also in load bearing structures. The architects prefer to design more transparent buildings. By increasing the transparency of buildings, the engineers can meet with special designing and construction problems for glazing and load bearing glass structures. Designing and calculating load bearing glass is a special area of civil engineering, yet the engineers are afraid of the breaking nature of glass, therefore glass constructions are mostly secondary or tertiary structural elements (in term of structural hierarchy of a building) [2]. There is also a lack of useful technical documents and standards especially for engineers in Hungary. An experimental study was carried out on load bearing capacity on non heat treated and tempered and laminated glass specimens, too, see Fig. 1

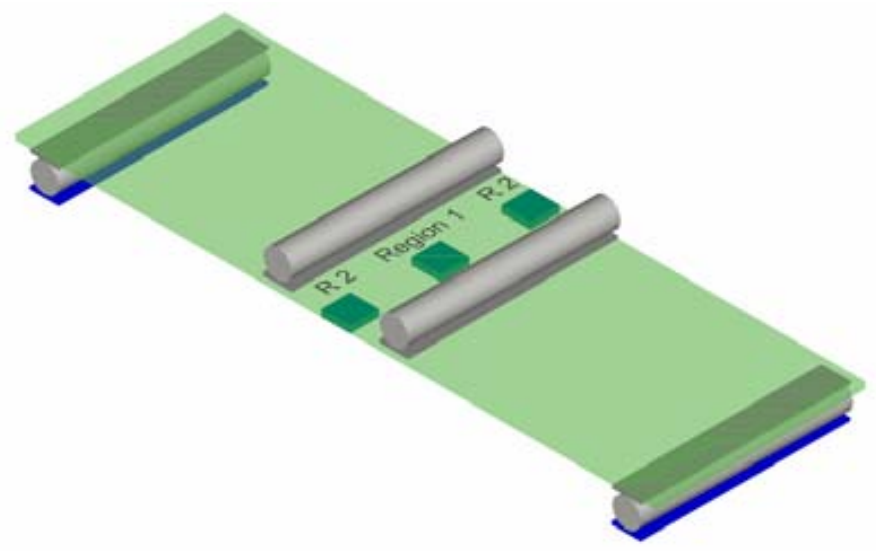

Fig. 1. Studied regions (Region 1 and Region 2) in four-point bending of the glass specimens [3]

\section{Tempered and non heat treated float glass}

Single glass is a homogeneous isotropic material with linearelastic behaviour. Glass has very high compressive strength and theoretically very high tensile strength, but the surface of the glass has many irregularities, which act as weaknesses when glass is subjected to tensile stress. These irregularities are 
caused by attack from and by contact with hard materials (harder than glass itself) and can be modified by moisture, which is always present in the air. Tensile strengths of around 10000 $\mathrm{N} / \mathrm{mm}^{2}$ can be predicted from the molecular structure, but glass normally fails at stresses considerably below $100 \mathrm{~N} / \mathrm{mm}^{2}$. The presence of the irregularities and their modification by moisture [4,5] contributes to the properties of glass which need consideration when performing tests of strength. Because of the high compressive strength, glass always fails under tensile stress. Since glass in buildings was introduced, the most important property for load resistance has been its tensile and bending strength [6].

Heat tempered glasses are produced by heating up the glass to approximately $650{ }^{\circ} \mathrm{C}$ and then cooled down to create compressive stresses within the external layers. Cooling rate defines if the glass is heat strengthened or tempered. Because of the resulting compressive stresses in the external layers, the tempered glass is approximately twice as strong as the heat strengthened glass of the same thickness [7]. The most dramatic and important difference between heat strengthened float and tempered glasses is the post failure characteristics of the products, i.e. their failure pattern, see Fig. 2, 3.

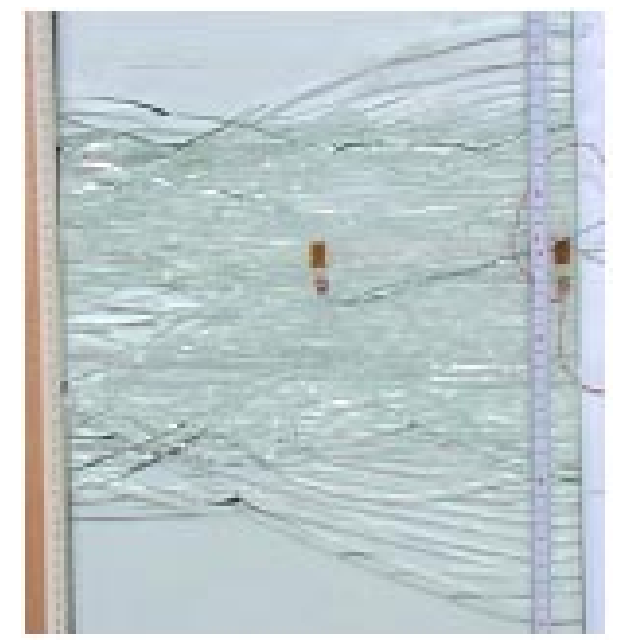

Fig. 2. Fracture pattern of float glass tested according to EN 1288-3:2000

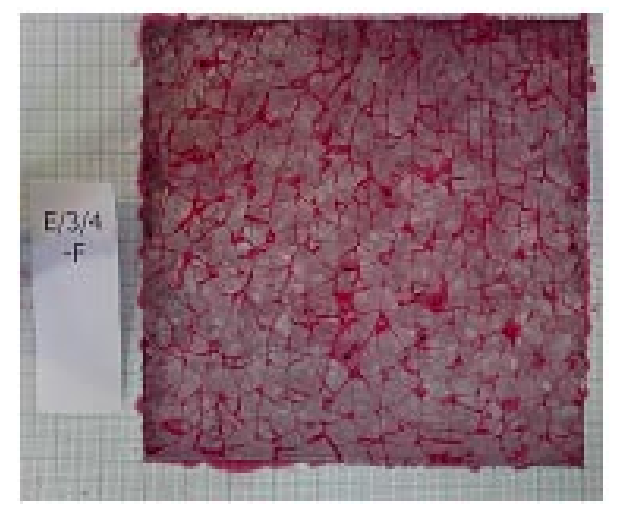

Fig. 3. Fracture pattern (painted) of tempered glass tested according to EN 1288-3:2000

\section{Bending strength of glass}

The following factors influence the bending strength of glass products:

a) heat treatment,

b) surface condition (e.g. non-slip characteristics for stairs),

c) rate and duration of loading,

d) area of surface stressed in tension,

e) relaxation [8],

f) ambient medium, through stress corrosion cracking as well as healing of surface damage in the glass [4],

g) age, i.e. time elapsed from the last mechanical surface treatment or modification to simulate damage [5],

h) ambient temperature,

i) edgework (roughness, region of initialization of cracking) [9],

j) laminate is influenced by interlayer material too (aging, delamination, behaviour at different temperatures or humidity, etc.) [10]

\section{Bending behaviour of laminated safety glass}

If tempered glass fractures, it falls apart into numerous small pieces, the edges of which are generally blunt. Interlayer is used between the glass panes in laminated glass products, which help to hold the fragments together if glass breaks. Thy mostly used interlayer is a kind of foil such as PVB (polyvinyl-butyral) or kind of resins (styrene). The mechanical behaviour of the composite is determined by the ability of the interlayer material to transfer shear between the glass panes. All parameters that influence bond also act on the structural behaviour of the composite.

\subsection{Physical characteristics of the interlayer}

The structural behaviour of laminated safety glass lies between two limits. The lower limit of the load bearing capacity is the so-called "layered limit", in which the glass panes react without shear bond. The upper limit of the load bearing capacity is the "monolithic limit" in which all glass panes are rigidly connected [11]. For both limits stresses in the glass pane can be calculated using the known formulas and models. In reality the maximum stress in the glass panes of the laminate lies between those two limits. In this research work resin and new type of foil EVA (ethyl-vinyl acetate) was used as interlayer material $[12,13]$. The bond in laminate is also influenced by the rheologic behaviour of the interlayer.

Fig. 4 and Table 1 indicate the influence of temperature on properties of polymer interlayer. The stress transition temperature (glassy region - transition region - rubbery plateau - flow zone) of polymers are important factors on the behaviour of laminated glass as a composite. The perfect bond in the laminate 
Tab. 1. Physical properties of tested resin and EVA interlayer and commonly used PVB [12, 14]

\begin{tabular}{|c|c|c|c|c|}
\hline & Unit & $\begin{array}{l}\text { RESIN } \\
\text { (Styrene } \\
\text { Unilam1418) }\end{array}$ & $\begin{array}{l}\text { EVA } \\
\text { (Ethylene Vinyl Acetate) }\end{array}$ & $\begin{array}{l}\text { PVB } \\
\text { (Polyvinyl Butyral) }\end{array}$ \\
\hline Tensile strength at $23^{\circ} \mathrm{C}$ & $\mathrm{N} / \mathrm{mm}^{2}$ & 3.6 & $14-22$ & $20<$ \\
\hline Elongation at $23^{\circ} \mathrm{C}$ & $\%$ & 160 & $465<$ & $250<$ \\
\hline Young's Modulus at $23^{\circ} \mathrm{C}$ & $\mathrm{N} / \mathrm{mm}^{2}$ & 12 & $1.2<$ & $1.5<(\sim 10)$ \\
\hline Poisson's ratio at $23^{\circ} \mathrm{C}$ & & $\sim 0.40$ & 0.32 & $\sim 0.50$ \\
\hline Stress transition temperature (vitrification) & ${ }^{\circ} \mathrm{C}$ & -31 & $\begin{array}{l}-28 \\
\text { (depending on the content of } \\
\text { softeners) }\end{array}$ & $\begin{array}{l}\sim+14 \\
\text { (depending on the content of soft- } \\
\text { eners) }\end{array}$ \\
\hline Water absorption & $\%$ & No data & $<0.01$ & $\begin{array}{l}\text { Air bubbles can generate around } \\
\text { the edge. Problem in bonding. }\end{array}$ \\
\hline Note & & - & $\begin{array}{l}\text { Also good in outdoor condi- } \\
\text { tion }\end{array}$ & Using between +15 and $60^{\circ} \mathrm{C}$. \\
\hline
\end{tabular}

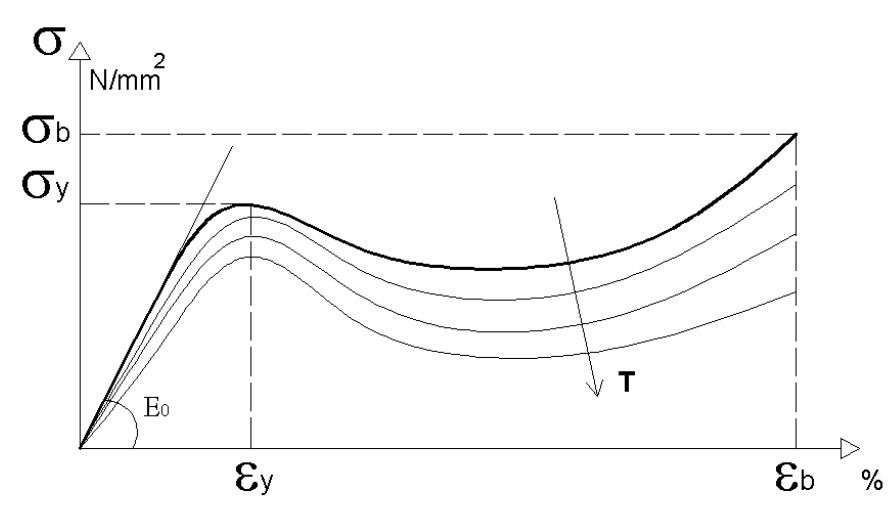

Fig. 4. Stress-strain diagram of polymers

depends also on the manufacturer. The better bond is not insured when the bonding process is performed around or below the glass transition temperature of the adhesive. Water content and aging of interlayer material can reduce both the adhesion to the glass surface and bond-strength [10,14]. The edge strength [9] of the laminate is also influenced by the interlayer material.

\section{Method of testing (four-point bending)}

Non heat treated and tempered single ply glass specimens of different thicknesses $6 \mathrm{~mm}, 12 \mathrm{~mm}$ and $19 \mathrm{~mm}$ and laminated ( $2 \times 6 \mathrm{~mm}, 3 \times 6 \mathrm{~mm})$ glass specimens with constant span of 1.0 $\mathrm{m}$ and width of $0.36 \mathrm{~m}$ were tested in a four-point bending, see Fig. 5 and Fig. 6. Interlayer materials were resin (cast in place styrene) or EVA (ethyl-vinyl-acetate) foil. There were tested specimens only with spacer and without interlayer material (between the glass panes near to the edges elastic strip width of 5 $\mathrm{mm}$ ). The load, temperature and deflection at mid-span and the strain at selected points (in Region 1 and Region 2, see Fig. 1) on the surface of the glass panes were measured in all tests. The test programme is a semi-dynamic short-term test. The experiments were carried out at room temperature $+23^{\circ} \mathrm{C}$ and also specimens were heated up to $+60^{\circ} \mathrm{C}$ or cooled down to $-20^{\circ} \mathrm{C}$. The heated or cooled specimens were isolated to provide an environment with constant temperature and humidity [3].

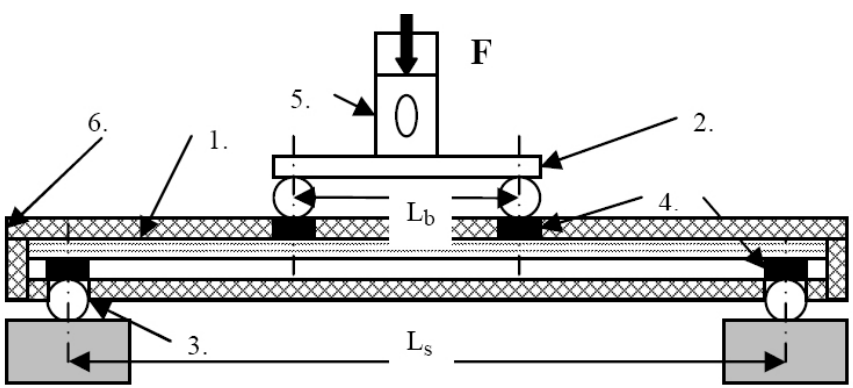

Fig. 5. Method of testing according to EN 1288-3 where, 1.: Specimen: $1100 \times 360 \mathrm{~mm}$; 2.: Bending roller; 3.: Supporting roller; 4.: Rubber strips (3 $\mathrm{mm}$ thick, accordance to ISO 48 [17]); 5.: custom-made transducer; 6.: custommade isolation ( $40 \mathrm{~mm}$ thick); $\mathrm{L}_{s}: 1000 \mathrm{~mm} ; \mathrm{L}_{b}: 200 \mathrm{~mm} ; t$ : thickness of the specimen (in this project $6 \mathrm{~mm}, 2 \times 6$ or $3 \times 6 \mathrm{~mm}, 12 \mathrm{~mm}, 19 \mathrm{~mm}$ )

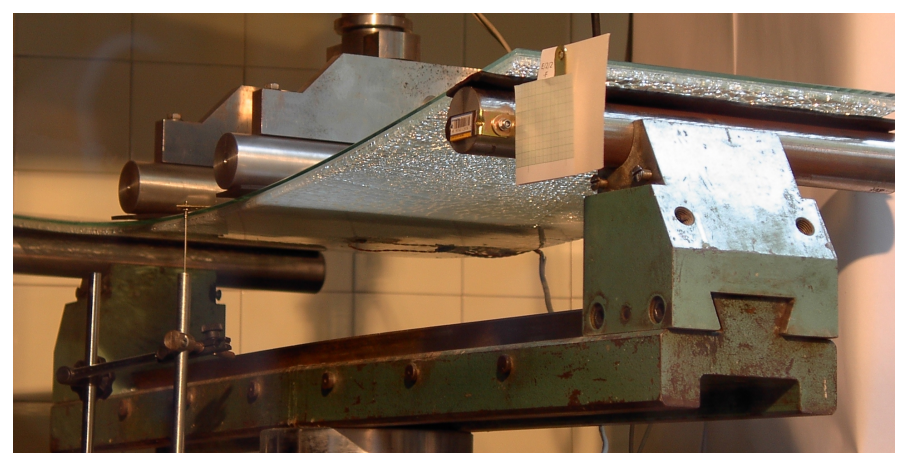

Fig. 6. Testing of laminated safety glass

\subsection{Calculation of bending strength}

Soda-lime silica glass products have a density of $2.5 \mathrm{~g} / \mathrm{cm}^{3}$. ASTM 1300-04 [18] gives in Appendix for Young's Modulus $71.7 \times 10^{3} \mathrm{~N} / \mathrm{mm}^{2}$ while EN $1288-3$ gives $70 \times 10^{3} \mathrm{~N} / \mathrm{mm}^{2}$. To determine the bending strength the following formula can be applied [1]:

$$
\sigma_{b B}=k\left[F_{\max } \frac{3\left(L_{s}-L_{b}\right)}{2 B t^{2}}+\sigma_{b G}\right]
$$

Bending stress imposed by the self-weight of the specimen:

$$
\sigma_{b G}=\frac{3 \rho g L_{s}^{2}}{4 t}
$$


where

$B \quad$ width of specimen ;

$t \quad$ thickness of specimen;

$L_{s} \quad$ distance between the centre lines of the supporting rollers;

$L_{b} \quad$ distance between the centre lines of the bending rollers;

$y \quad$ central deflection of the specimen;

$k=k_{e}$ dimensionless factor as function of $y / t$ to determine the stress at the mid of $\operatorname{span} k=1$;

$\sigma_{b B} \quad$ bending strength;

$\sigma_{b G}$ bending stress imposed by the self-weight of the specimen.

Factor $k$ is used when it is required to determine the bending strength of glass where the effects of the edge are important. For calculating the overall bending strength or equivalent bending strength of the surface area, including the edges the value $k=1$ shall be used.

For calculating the bending strength or equivalent bending strength of the free edges of the glass pane $k=k_{e}$ shall be used.

The appropriate value of $\mathrm{k}_{e}$ for use in Eq. 1 shall be obtained from Fig. 7, which gives the value of $\mathrm{k}_{e}$ as a function of the value of $y / t[6]$.

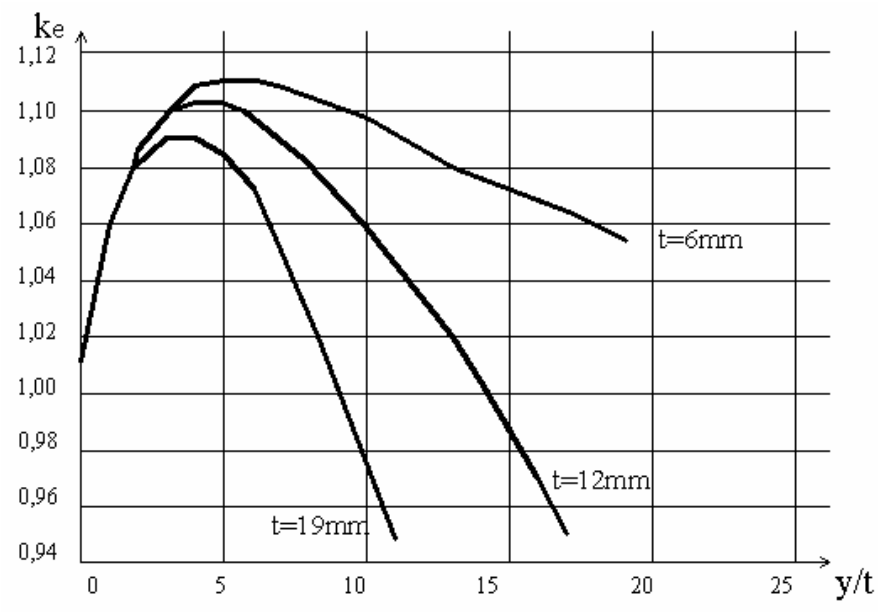

Fig. 7. Dimensionless factor $\mathrm{k}_{e}$ as a function of $y / t$ [6]

Simple theory (beam model) assumes that there are no stresses across the width of a beam when it is subjected to bending along its length, but the Poisson effect $(\mu=0,23$ is given for float soda lime silicate glass) generates significant stresses across the width of wide beams, so the longitudinal stress cannot be regarded as uniform across the width. The value $k$ takes into account this effect to calculate the bending stress developed at the edges of the beam. Using plate model to calculate stresses and deflection could also highlight the difference between stress in Region1 and Region2, but Region2 is affected by the edgework too.

\subsection{Testing parameters and testing program}

To study the effects of the interlayer and temperature on the load bearing capacity of the glass specimens following factors were determined:

Constants were: rate (type) of loading; supporting; geometry; surface treatment; edge work; etc.

Variables were: tempering; type of interlayer see Table 1 (resin, EVA or without interlayer); piece of glass layer in laminate; temperature. Fig. 8 illustrates the schematic diagram of the testing program.

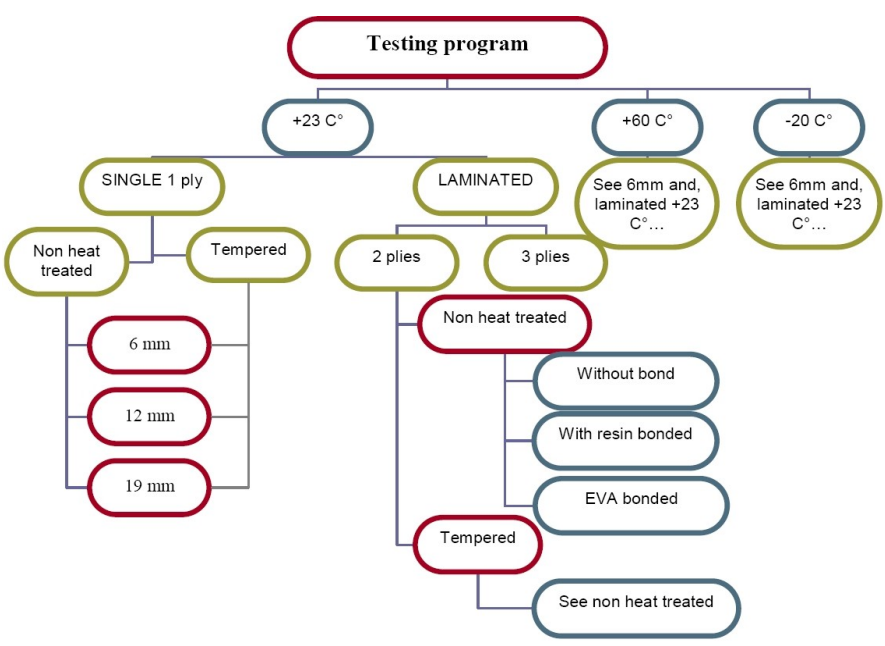

Fig. 8. Schematic diagram of the testing program

\section{Test results}

\subsection{Effect of tempering on load bearing capacity of single glass}

The average maximal surface stresses $\sigma$ and the bending strength $\sigma_{b B}$ of the single glass specimens are summarized in the following table. By strain gage measurements the surface stresses have been calculated with Hook's law. There have been calculated with Eq. 1 the mid pane strength $\sigma_{b B}$ (Region 1) and edge strength $\sigma_{\mathrm{bBedge}}$ (Region 2 ) on the lower surface of single non heat treated float $\left(F_{1}\right)$ and tempered $\left(E_{1}\right)$ glass specimens.

Table 2 indicates the surface stresses at maximal force and the calculated bending strength of the single $6 \mathrm{~mm}, 12 \mathrm{~mm}$, and $19 \mathrm{~mm}$ thick glass specimens are different. The surface stresses are $\sim 17 \%$ lower than the bending strength of the $6 \mathrm{~mm}$ thick glass specimens. With thinner than $6 \mathrm{~mm}$ glass panes - both tempered or float - the maximal surface stresses should be considered. The bending strength of tempered specimens is always higher than the surface stresses of them. Fig. 9 indicates the size effect of bending strength of glass panes. Using the fitted curves and log-log plot of the graphs straight lines are indicating the size effect. For tempered glass pane the slope is about 1:6,25 which indicates small size effect and the reason for the size effect is rather stochastic distribution of the defects in the glass pane (Weibull type size effect, otherwise to call statistical size effect). For float glass pane the slope is about 1:2.6 which is strong size effect and the reason for that is development of large cracks. The linear elastic fracture mechanics provides a good model for this type of glass panes.

Bending strength of $6 \mathrm{~mm}$ thick single tempered glass spec- 
Tab. 2. Summarizing table of measured values and calculated surface stress and bending strength of single float (F_1) and tempered (E_1) glass specimens.

\begin{tabular}{|c|c|c|c|c|c|c|c|c|c|c|c|c|}
\hline \multirow{4}{*}{ 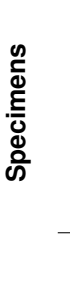 } & \multirow{3}{*}{$t$} & \multicolumn{4}{|c|}{ Measured values (avg.) } & \multicolumn{2}{|c|}{$\begin{array}{c}\text { Measured } \\
\text { Stress: } \sigma=E \varepsilon\end{array}$} & \multicolumn{5}{|c|}{ Calculated values (avg.) } \\
\hline & & \multirow{2}{*}{$\begin{array}{l}\mathbf{F}_{\max } \\
\text { avg. }\end{array}$} & \multirow{2}{*}{$\begin{array}{l}\mathbf{y} \\
\operatorname{avg} .\end{array}$} & \multicolumn{2}{|c|}{$\varepsilon_{\max , a v g}$} & \multirow{2}{*}{$\begin{array}{l}\text { Mid } \\
\text { Lower } \\
\text { pane }\end{array}$} & \multirow{2}{*}{$\begin{array}{l}\text { Edge } \\
\text { Lower } \\
\text { pane }\end{array}$} & \multirow[t]{2}{*}{$\sigma_{b G}$} & \multirow[t]{2}{*}{$\sigma_{b B}$} & \multirow[t]{2}{*}{$y / t$} & \multirow{2}{*}{$\begin{array}{l}\mathbf{k}_{e} \\
\text { edge }\end{array}$} & \multirow{2}{*}{$\sigma_{b B}$} \\
\hline & & & & $\begin{array}{l}\text { Mid } \\
\text { Lower pane }\end{array}$ & $\begin{array}{l}\text { Edge } \\
\text { Lower pane }\end{array}$ & & & & & & & \\
\hline & $\mathrm{mm}$ & $\mathrm{kN}$ & $\mathrm{mm}$ & $\mu \mathrm{m} / \mathrm{m}$ & $\mu \mathrm{m} / \mathrm{m}$ & $\mathrm{N} / \mathrm{mm}^{2}$ & $\mathrm{~N} / \mathrm{mm}^{2}$ & $\mathrm{~N} / \mathrm{mm}^{2}$ & $\mathrm{~N} / \mathrm{mm}^{2}$ & - & - & $\mathrm{N} / \mathrm{mm}^{2}$ \\
\hline \multirow{3}{*}{ E_1 } & $6 \mathrm{~mm}$ & 1.62 & 63.34 & 1841.26 & 2041.28 & 128.9 & 142.9 & 3.7 & 154.5 & 10.30 & 1.09 & 168.8 \\
\hline & $12 \mathrm{~mm}$ & 7.94 & 46.15 & 2563.46 & 2921.36 & 179.4 & 204.5 & 1.9 & 186.7 & 3.81 & 1.11 & 207.0 \\
\hline & $19 \mathrm{~mm}$ & 15.52 & 24.73 & 2075.88 & 2274.99 & 145.3 & 159.2 & 1.2 & 145.3 & 1.29 & 1.07 & 155.0 \\
\hline \multirow{3}{*}{ F_1 } & $6 \mathrm{~mm}$ & 0.47 & 18.76 & 514.17 & 565.17 & 36.0 & 39.6 & 3.7 & 47.0 & 2.87 & 1.10 & 51.7 \\
\hline & $12 \mathrm{~mm}$ & 2.66 & 17.41 & 1053.20 & 1053.32 & 73.7 & 73.7 & 1.9 & 63.8 & 1.42 & 1.07 & 68.3 \\
\hline & $19 \mathrm{~mm}$ & 7.21 & 11.87 & 1125.55 & 1188.82 & 78.8 & 83.2 & 1.2 & 68.1 & 0.62 & 1.04 & 71.0 \\
\hline
\end{tabular}

Fig. 9. Ratio of calculated bending strengths and surface stresses of single glass specimens with different thicknesses in, \%.

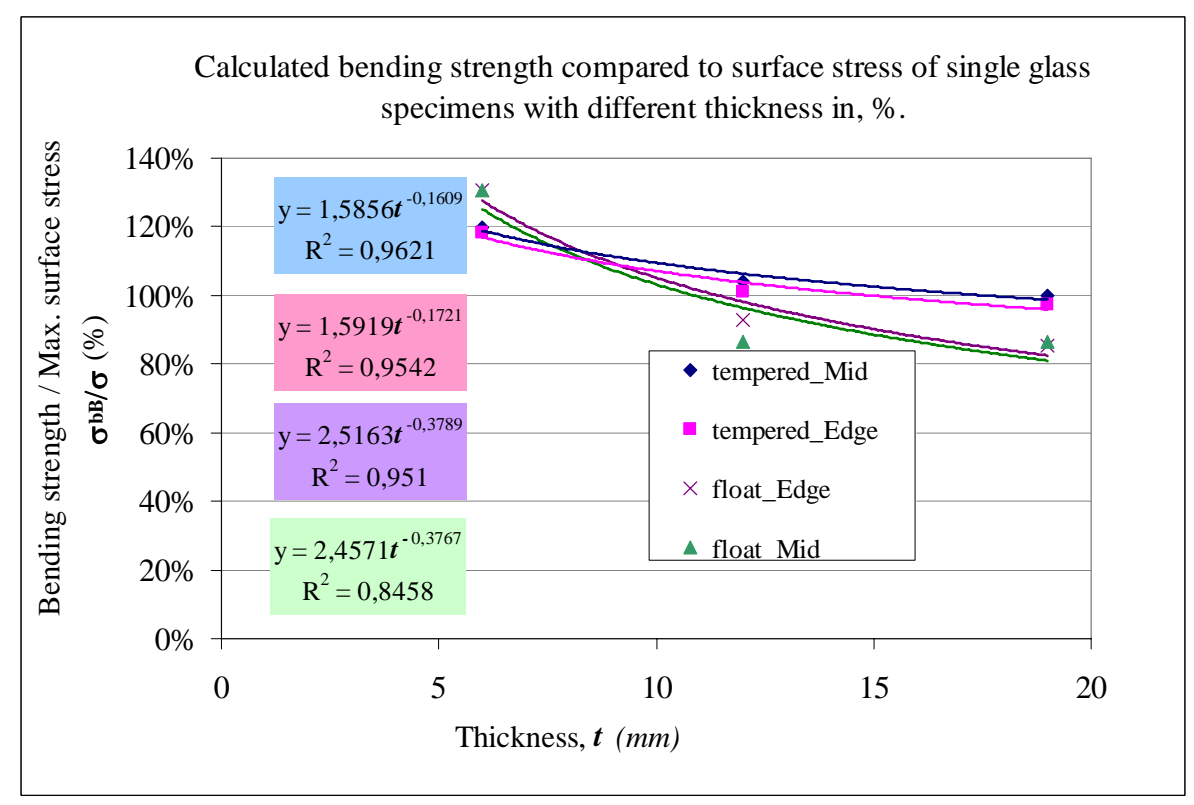

imen is $\sim 117 \%$ higher than the surface stress. The bending strength of tempered glass specimens will increase in proportion to surface stress by decreasing thickness. The bending strength of float glass specimens will decrease in proportion to surface stress by increasing thickness (bending strength of $19 \mathrm{~mm}$ thick single float glass specimen is $\sim 80 \%$ of the surface stress). The surface stresses are more influenced by the surface condition of glass than the bending strength. Penetration of the surface by hard, sharp particles which are caused by machining, abrasion, scratching are the initial locations of cracks, which can develop and propagate quickly in glass. The edge region of glass due to edgework contains more defects. If glass fractures, it fails mainly at the edges first and the cracks will propagate in the direction of mid pane. Because of the high crack propagation velocity in glass $(v=1480 \mathrm{~m} / \mathrm{s})[15,16]$ it can be observed only with high-speed cameras, which are able to record the crack propagation in glass pane. Strain gage measurement indicated that the higher stresses were measured in the edge region (Region 2, see Fig. 1). When the surface stress reaches the surface strength of the pane, it fractures. The surface strength of tempered glass is influenced by the tempering process, for tempered glass the compressive stresses in the surface layer are about $150 \mathrm{~N} / \mathrm{mm}^{2}$ [3, 11].

The maximal force was measured and can be also calculated:

$$
F_{\max _{\text {calc. }}}=\frac{2 B t^{2}\left(\sigma_{b B}-\sigma_{b G}\right)}{3\left(L_{s}-L_{b}\right)}
$$

The maximal deflection was measured and can be also calculated:

$$
y_{\max _{\text {calc. }}}=\frac{3 F_{\max }}{4 E B t^{3}}\left[\frac{L_{S}^{3}}{3}+\frac{L_{b}^{3}}{6}-\frac{L_{S} \cdot L_{b}^{2}}{2}\right]
$$

The stresses compared to surface tension stresses have shown that in-plane stresses lead earlier to failure than bending stresses, especially in the case of tempered and thin float $(t<10 \mathrm{~mm})$ glass panes, see Table 2. Fig. 9. In the case of taking the bending strength equal to ultimate surface strength for tempered glass maximum $150 \mathrm{~N} / \mathrm{mm}^{2}$ the maximal force is calculated with Eq. 3. The ultimate surface strength for tempered glass depends on the manufacturers, also standards prefer to temper glass to induce stresses in outer layer $120-150 \mathrm{~N} / \mathrm{mm}^{2}$. Table 3 indicates that there are differences in calculated force and deflection compared to the measured values. 
Tab. 3. Summarizing table of measured values and calculated surface stress and bending strength of single float $\left(F_{1}\right)$ and tempered $\left(E_{1}\right)$ glass specimens.

\begin{tabular}{|c|c|c|c|c|c|c|}
\hline \multirow{2}{*}{ Specimen } & \multirow{2}{*}{$\begin{array}{l}\text { Thickness } \\
\text { t }\end{array}$} & \multicolumn{2}{|c|}{$\begin{array}{l}\text { Measured values } \\
\text { (avg.) }\end{array}$} & \multicolumn{3}{|c|}{$\begin{array}{c}\text { Calculated values (avg.) } \\
\text { Tempered: } \sigma_{b G}=\sigma=150 \mathrm{~N} / \mathrm{mm}^{2}\end{array}$} \\
\hline & & $\mathbf{F}_{\text {max.,avg. }}$ & $\begin{array}{l}\mathbf{y}_{\text {avg. }} \\
\mathrm{mm}\end{array}$ & $\mathbf{F}_{\text {max }, \text { calc. }}$ & $\begin{array}{l}\mathbf{y}_{\text {calc. }} \\
\text { (with measured) } \\
\mathbf{F}_{\text {max.,avg.) }} \\
\mathrm{mm}\end{array}$ & $\begin{array}{l}\mathbf{y}_{\text {calc. }} \\
\text { (with calculated) } \\
\mathbf{F}_{\text {max }, \text { calc.) }} \\
\mathrm{mm}\end{array}$ \\
\hline \multirow{3}{*}{ E_1 tempered } & $6 \mathrm{~mm}$ & 1.62 & 63.34 & 1.57 & 70.63 & 68.50 \\
\hline & $12 \mathrm{~mm}$ & 7.94 & 46.15 & 6.36 & 43.27 & 34.68 \\
\hline & $19 \mathrm{~mm}$ & 15.52 & 24.73 & 16.03 & 21.31 & 22.01 \\
\hline
\end{tabular}

Fig. 10. Effect of temperature on load bearing capacity of $6 \mathrm{~mm}$ thick float glass specimen, where on Force-Deflection diagram the symbols mean: E- tempered glass; F- non heat treated float glass;

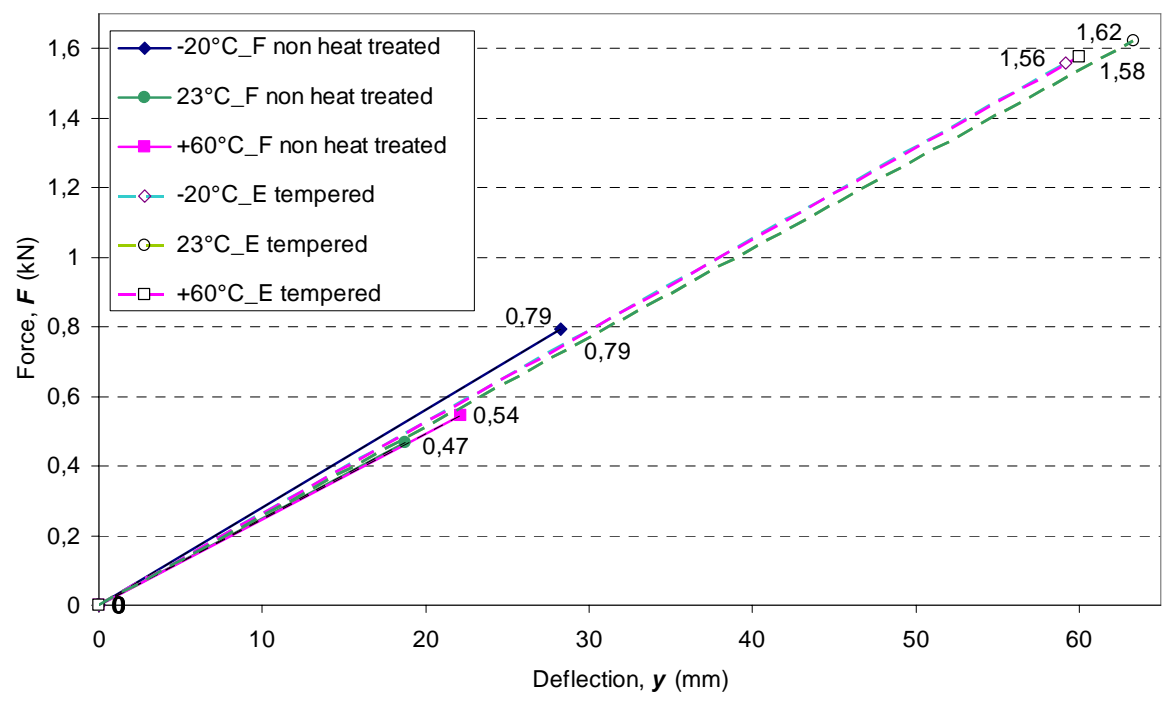

By using Eq. (3), which is a common formula to calculate the maximal force the effect of: rate of loading and surface and edge treatment, tempering, temperature etc. which are influencing factors on glass, can't be taken into account.

Eq. 4 gives the deflection of the glass pane considering beam model and small deflection theorem. However the deflection is large according the data of the tests. This could give the explanation for the difference between the calculated and measured displacement. The deflection in this tests caused by self weight are about $1 \%$ of total maximal deflection in case of thick $(12 \mathrm{~mm}$ and $19 \mathrm{~mm})$ specimens and is about $2.2 \%(=1.52 / 68.5)$ of $6 \mathrm{~mm}$ thick specimen, which can be neglected in Eq. 4 because the accuracy of the engineering measurement is also about $2 \%$. But it is important to notice that large scale glazing units can have significant deflection caused by their self weight which can't be neglected and is dependant from the supporting condition.

The calculated maximal deflection ( $\mathbf{y}_{\text {calc. }}$ with measured $F_{\text {max,avg. }}$ ) of $6 \mathrm{~mm}$ glass specimen is overestimated $11 \%$, but $14 \%$ underestimated of $12 \mathrm{~mm}$ and $19 \mathrm{~mm}$ thick specimens.

An ultimate surface strength can be considered, which should be reduced by safety factors to safe calculation of ultimate force $\left(\mathbf{F}_{\text {max }, \text { calc. }}\right)$ or desing force $\left(\mathbf{F}_{\text {max }, \text { design. }}\right)$ of a glass pane.

\subsection{Effect of temperature on load bearing capacity of single glass}

Single float and tempered glass was also tested at different temperatures to determine the influence of temperature on the load bearing capacity of glass.

The temperature does not have an effect on the load bearing capacity of tempered glass. Not heat treated float glass specimens were more affected by temperature especially at $-20^{\circ} \mathrm{C}$, which behave more rigidly than at room temperatures, see Fig. 10 .

By increasing temperature, the measured strains on lower surface of glass specimens increased in both Regions (Region 1, and Region 2). Edge stresses are always about $10 \%$ higher than the mid pane stresses. Reaching the maximum value of strains in edge region, which is about $700 \mu \mathrm{m} / \mathrm{m}$ of float glass and $2000 \mu \mathrm{m} / \mathrm{m}$ of tempered specimens, the fracture occurred. Table 4 indicates the measured values of strains before fracture of specimens in Region1 and Region2 and the calculated surface stresses. To calculate the surface stresses of non heat treated specimens at $-20^{\circ} \mathrm{C}$, Young's modulus $\mathrm{E}=74 \times 10^{3} \mathrm{~N} / \mathrm{mm}^{2}$ should be applied.

\subsection{Effect of laminating material on load bearing capacity of glass}

The Fig. 11 indicates laminated 3 plies tempered glass specimens with different interlayer, EVA (E_3_F) or resin (E_3_R) or without laminating material (E_3_D). At room temperature the EVA laminated specimens behave more rigidly than with resin laminated specimens. Taking the force $F=4 \mathrm{kN}$ the measured different deflections of laminates indicate the layered limits (deflection of single glass is $\sim 6 \mathrm{~mm}<\mathrm{y}<$ without interlayer is 
Tab. 4. Effect of temperature on strain and surface stress of $6 \mathrm{~mm}$ thick single glass specimens

\begin{tabular}{|c|c|c|c|c|c|}
\hline \multirow[t]{2}{*}{$\begin{array}{l}\text { Strain and surface stress of } \\
6 \mathrm{~mm} \text { thick glass specimens }\end{array}$} & $\begin{array}{l}\text { Mid } \\
\text { of Lower pane }\end{array}$ & $\begin{array}{l}\text { Edge } \\
\text { of Lower pane }\end{array}$ & $\begin{array}{l}\text { Young's modulus } \\
\text { E }\end{array}$ & $\begin{array}{l}\text { Mid } \\
\text { of Lowerpane }\end{array}$ & $\begin{array}{l}\text { Edge } \\
\text { of Lowerpane }\end{array}$ \\
\hline & $\begin{array}{l}\varepsilon_{\text {max.,avg. }} \\
\mu \mathrm{m} / \mathrm{m}\end{array}$ & $\begin{array}{l}\varepsilon_{\text {max.,avg. }} \\
\mu \mathrm{m} / \mathrm{m}\end{array}$ & $\begin{array}{l}\times 10^{3} \\
\mathrm{~N} / \mathrm{mm}^{2}\end{array}$ & $\begin{array}{l}\sigma_{\text {max., avg }} \\
\mathrm{N} / \mathrm{mm}^{2}\end{array}$ & $\begin{array}{l}\sigma_{\text {max., avg }} \\
\mathrm{N} / \mathrm{mm}^{2}\end{array}$ \\
\hline$-20^{\circ} \mathrm{C}$ & 631.71 & 671.25 & 74 & 46.7 & 49.7 \\
\hline $\mathbf{F}$ float & 638.85 & 704.46 & 70 & 44.7 & 49.3 \\
\hline $60^{\circ} \mathrm{C}$ & 689.45 & 728.72 & 70 & 48.3 & 51.0 \\
\hline$-20^{\circ} \mathrm{C}$ & 1903.06 & 2131.26 & 70 & 133.2 & 149.2 \\
\hline E tempered & 1952.49 & 2068.81 & 70 & 136.7 & 144.8 \\
\hline $60^{\circ} \mathrm{C}$ & 2177.57 & 2262.52 & 70 & 152.4 & 158.4 \\
\hline
\end{tabular}

Fig. 11. Effect of interlayer on load bearing capacity of laminated tempered glass, where on ForceDeflection diagram the symbols mean: E- tempered glass; 3-pieces of glass layers, different interlayer EVA (E_3_F) or resin (E_3_R) or without interlayer (E_3_D)

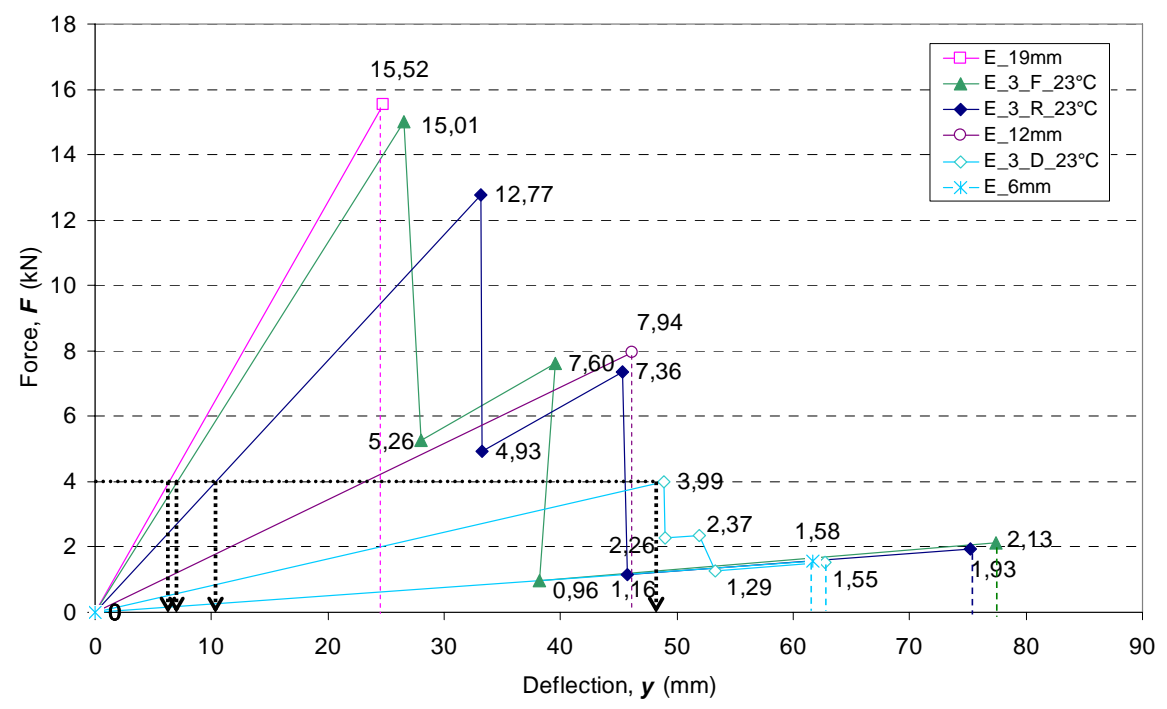

$\sim 48 \mathrm{~mm}$ ) of the laminated glass. EVA is such that the laminated glass may be considered as a solid one there is no slip between the glass layers due to the shear deformation of the EVA layer. In case of applying resin there is considerable slip between the glass layers due to the large shear deformation of the resin layer.

If we join two slabs together, one on top of the other, with a shear-resistant connection, then the loads can no longer be split in proportion to the strengths but instead are carried by a composite unit. The strength in the glass panes are influenced by the shear transfer of the interlayer. If they are strong bonded and the strain of the interlayer is small, the composite behaves relatively monolithic, see Fig. 12] [3].

The load bearing capacity at $23^{\circ} \mathrm{C}$ is 4 times higher of EVA laminate and 3 times higher of resin laminate than of the laminate without interlayer. The interlayer has great influence on the post failure behaviour.

When the first pane fractures, the maximal force falls on the level of $\sim 35 \%$ of the maxima and starts to increase up to $150 \%$ while the deflection is increasing too, see Fig 11 When the second glass layer fractures, the force falls on the same level as the load-deflection of a single glass pane, and then starts to increase up to the maximal load bearing capacity of a single 6 $\mathrm{mm}$ glass pane till it fractures.

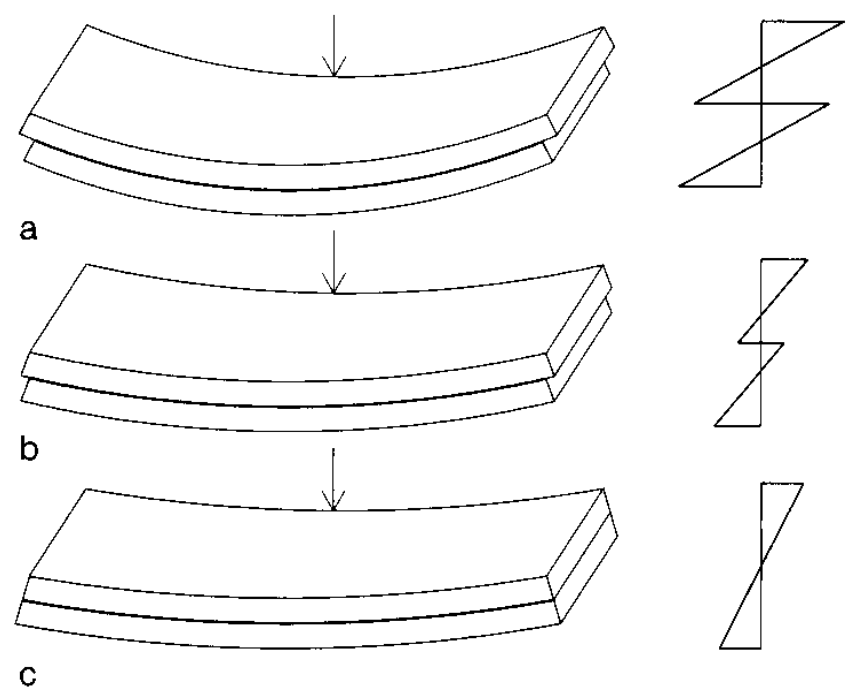

Fig. 12. Deflection behaviour and stress distribution in, a) panes laid without bond on top of each other, b) elastically bonded laminated safety glass, c) rigidly bonded or monolithic panes [11].

\subsection{Effect of temperature on load bearing capacity of lami- nated glass}

The results showed that the behaviour of the interlayer is influenced by the temperature for both non heat treated laminates and for tempered laminates. At higher temperatures $\left(+60 \mathrm{C}^{\circ}\right)$ both interlayer material will soften. The viscosity of the resin 
will increase and the EVA increases too. At lower temperatures $\left(-20 \mathrm{C}^{\circ}\right)$ the resin interlayer behaves more rigidly. It has an effect on the load bearing capacity of the laminate, Fig. 13 .

The deflections at force $F=4 \mathrm{kN}$ with resin laminated tempered glass specimens are at $-20{ }^{\circ} \mathrm{C}: 17 \mathrm{~mm}$; at $+23{ }^{\circ} \mathrm{C}$ : $23 \mathrm{~mm}$; at $+60{ }^{\circ} \mathrm{C}: 38 \mathrm{~mm}$, where of EVA laminate are at $-20{ }^{\circ} \mathrm{C}: 18 \mathrm{~mm}$; at $+23{ }^{\circ} \mathrm{C}: 21 \mathrm{~mm}$; at $+60{ }^{\circ} \mathrm{C}: 26 \mathrm{~mm}$, see Fig. 13 . Fig. 14 .

The EVA bonded laminates are more rigidly bonded at room temperatures and at $+60{ }^{\circ} \mathrm{C}$ than with resin bonded specimens. The results showed that the EVA-layer had a better bearing capacity at room temperatures or higher temperatures. For changing climate conditions the using of EVA interlayer is recommended.

With the testing of tempered laminated glass at room temperature, the failure of the specimen in the case of EVA-layer was always the fracture of glass and not of the interlayer, but in the case of non heat treated specimens the interlayer was also damaged. At $+60^{\circ} \mathrm{C}$ the fracture of all laminated specimens was the failure of glass and sometimes the interlayer too. The shear composite effect should be neglected especially under higher temperature and long-term-loads when the interlayer tends to creep.

The conditions or circumstances which lead to delamination instead of breaking of glass can be summarized:

- type of interlayer (viscoelastic nature of interlayer on different temperatures),

- poor adhesion or shear bond is not ensured between the glass panes,

- high temperatures,

- adsorption properties or aging of interlayer,

- long-term-loads and when the interlayer tend to creep etc.

The exposition classes for glazing (climatic zone or indoor/outdoor units, see Fig. 15,16 and Fig. 17) should be also determined in standards. Recommended testing temperature for laminated glass should depend on the exposition class of it. Fig. 16 illustrate a bridge for passageway (Gresham Palace, Budapest) with non slippery sand blasted laminated glass in outdoor conditions. Fig. 15 and Fig. 17 illustrate glass slabs (in Sándor and Gresham Palace. Budapest) in indoor conditions without surface treatment.

\section{Conclusions}

An experimental study was carried out to analyse the effect of tempering and influence of interlayer material and temperature on the structural behaviour of glass pane.

The results of these experiments can be thus summarized:

Before the fracture of glass pane the deflections can be high especially in the case of single glass. Deflections of glass pane should be limited also because of the sealing and watertightness, and not to override the adhesion strength by large deformations of glass panes.

The stresses, compared to surface tension stresses, have shown that in-plane stresses lead earlier to failure than bending stresses, especially in the case of thin glass panes.

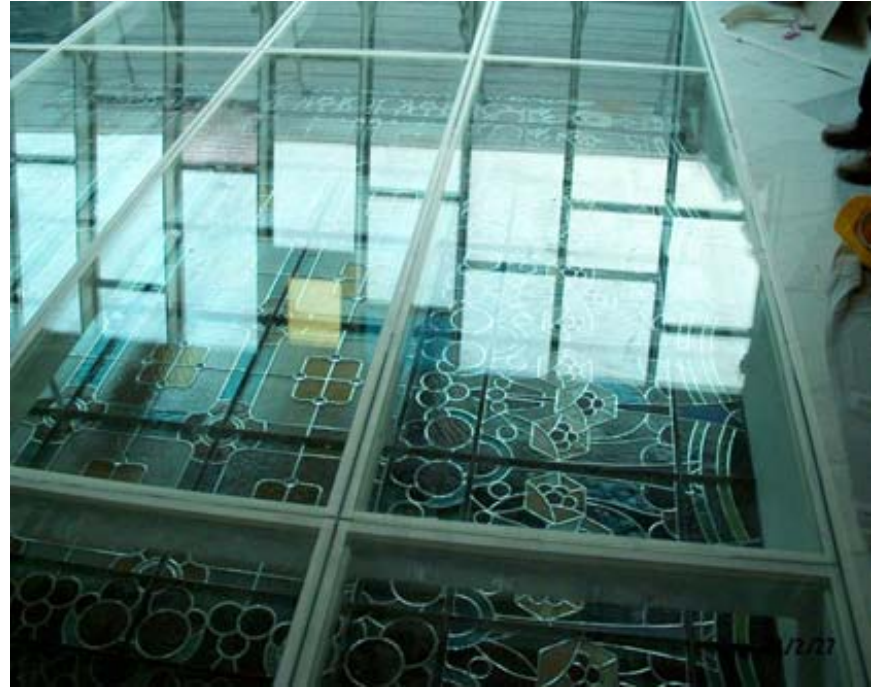

Fig. 15. Loadbearing "Kossuth, and Andrássy-bridge" Glass Slabs in Gresham Palace, calculations by K. Pankhardt, in 2002

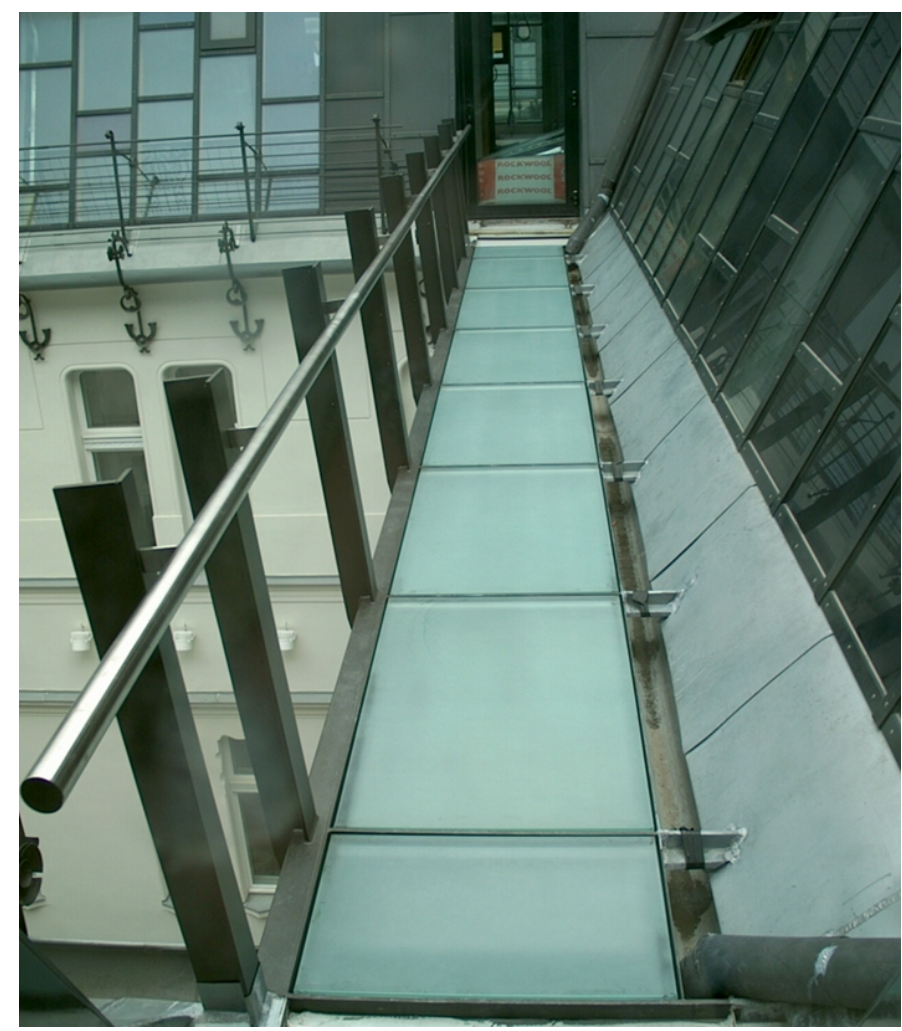

Fig. 16. "Gresham-bridge" cable tensioned bridge in Gresham Palace, calculations of glass and steel construction by K. Pankhardt, in 2002

By increasing temperature of glass specimens, the measured strains on lower surface increased in both Regions (Region 1, and Region 2). Edge stresses are always about $10 \%$ higher than the mid pane stresses. Reaching the maximum value of strains in edge region the fracture occurred, therefore the effect of the edge quality is important on load bearing and durability of glass. The decrease of the edge stresses decreases the load bearing capacity.

The viscoelastic nature of the interlayer material has an effect on the load bearing capacity of the laminate. For changing climate conditions [19] the using of EVA interlayer is recom- 
Fig. 13. Effect of temperature on loadbearing capacity of composite (laminate) where on ForceDeflection diagram the symbols mean: E- tempered glass, R- with resin laminated, 2- pieces of glass layers

Fig. 14. Effect of temperature on loadbearing capacity of composite (laminate) where on ForceDeflection diagram the symbols mean: E- tempered glass, F- with EVA foil laminated, 2- pieces of glass layers

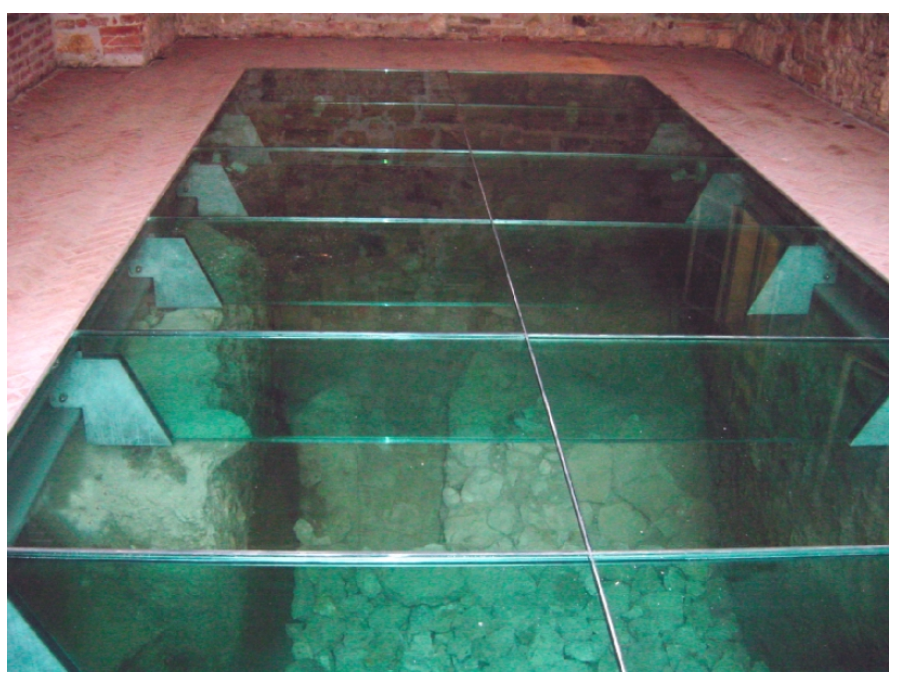

Fig. 17. Load bearing glass slab in Sándor Palace, calculations of glass and steel construction by K. Pankhardt, in 2001
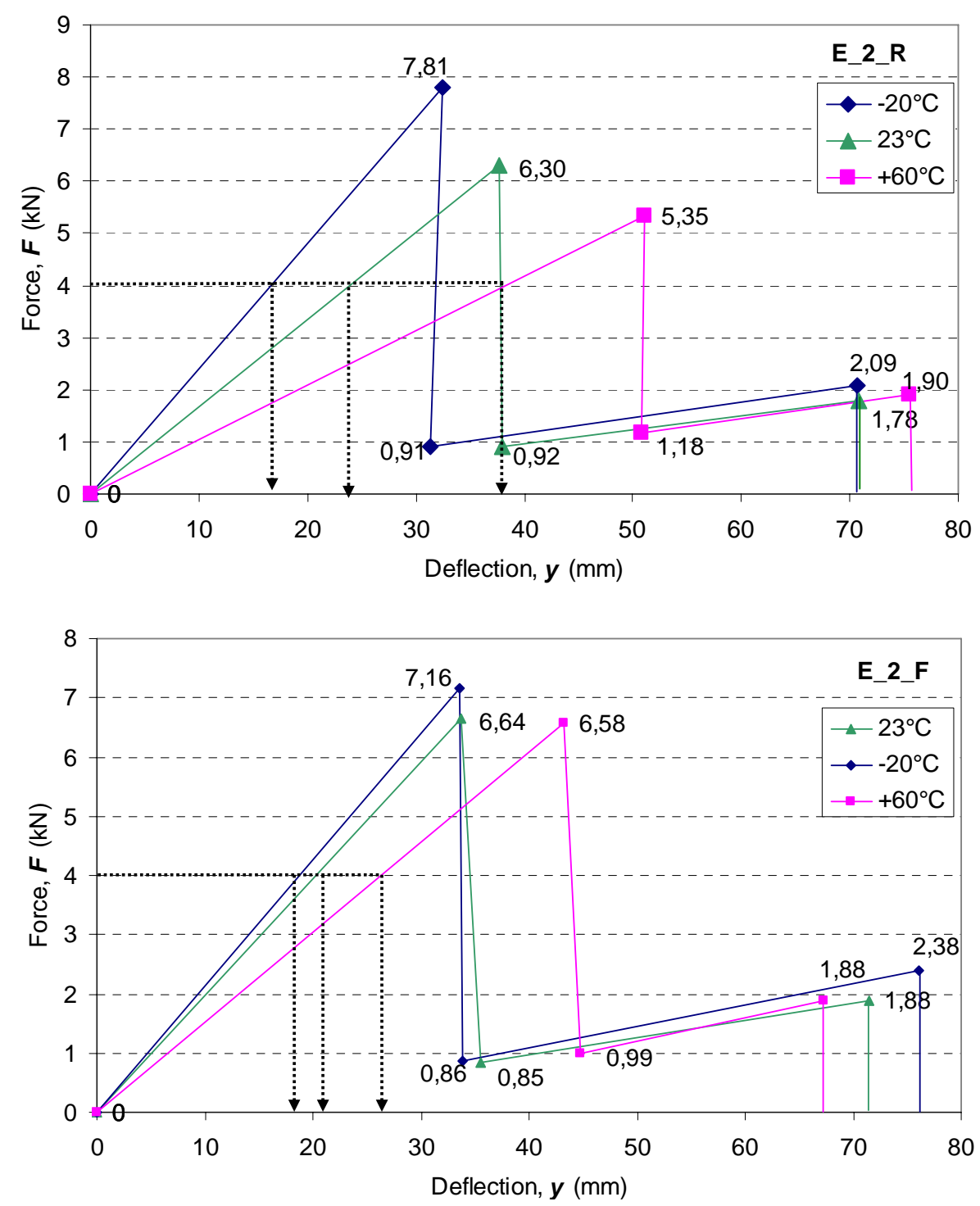

mended. The exposition classes for glazing (climatic zone or indoor/outdoor units etc.) should be also determined in cods or standards. Recommended testing temperature for laminated glass specimens should be determined depending on the exposure classes. The shear composite effect should be neglected especially under higher temperature and long-term-loads and when the interlayer tends to creep.

The remaining stability of glass depends also on the interlayer. The maximal load bearing capacity and load bearing capacity after fracture (post-failure behaviour) of the glass should be also obtained when glass is used in „first ordery" structures such as beams, columns, slabs etc. or when it is used in overhead areas like roofs or canopies where high safety demands have to be granted.

\section{References}

1 EN 1288-3: 2000: Glass in Building - Determination of the bending strength of glass - Part 3: Test with specimen supported at two points (four-point bending), Brussels, 2000. CEN.

2 Pankhardt K, Load bearing glass structures, Periodica Polytechnica, Civil engineering 48 (2004), no. 1-2, 157-172.

3 Pankhardt K, Balázs LGy, New opportunities of structural glazing, load- 
bearing glass structures: Responding to tomorrow's challenges in structural engineering Report, IABSE Symposium Budapest 2006. the whole paper on $\mathrm{CD}$ with 11 pages.

4 Wiederhorn SM, Influence of water vapor on crack propagation in sodalime glass, J. Am. Ceram. Soc. 50 (1967), 407-414, DOI 10.1111/j.11512916.1967.tb15145.x.

5 Wiederhorn SM, Bolz LH, Stress corrosion and static fatigue of glass, J. Am. Ceram. Soc. 53 (1970), 543-548, DOI 10.1111/j.11512916.1970.tb15962.x.

6 Glass in Building - Determination of the bending strength of glass - Part 1:Fundamentals of testing glass, CEN, Brussels, 2000. EN 1288-1:2000.

7 Greaves N, Glass in class, Specialfeature: Materials, Physics Education 40 (2005), 422-429, DOI 10.1088/0031-9120/40/5/001.

8 Kollár L, A mérnöki stabilitáselmélet különleges problémái, Akadémiai kiadó, Budapest, 2006.

9 Gulati S, Roe T, Vitkala J, Importance of edge finish on thermal tempering, Glass Processing Days (18), 2005, pp. 422-429.

10 Glick SH, Pern FJ, Watson GL, Tomek D, Raaff J, Performance Degradation Of Encapsulated Monocrystalline-Si Solar Cells Upon Accelerated Weathering Exposures, Proc. of 2001 NCPV Program Review Meeting, Lakewood co, 2001, pp. 307-308.

11 Schittich, Glass Construction Manual, Birkhauser Publishers, 1999.

12 Technical datasheet of UNILAM 1418 resin, given by the manufacturer Unilam.

13 Technical guide for the application of EVASFE to laminated glass, given by the manufacturer Bridgestone.

14 Van Duser A, Jagota A, Bennison J, Analysis of Glass/Polyvinyl Butyral Laminates Subjected to Uniform Pressure, Journal of Engineering Mechanics 125 (1999), no. 4, 435-442.

15 Denoyer J, Pollack H, Measurements of the velocity of crack propagation in glass plates, Bulletin of the Seismological Society of America 53 (1963), 87-93.

16 Cannon DD, Musso CS, Williams JC, Eagar TW, Analysis of Brittle Fracture of Soda Glass Bottles under Hydrostatic Pressure, Journal of Failure Analysis and Prevention 4 (2004), no. 5, 72-77, DOI 10.1361/15477020420800. ASM International 1547-7029.

17 Rubber, vulcanized or thermoplastic - Determination of hardness (hardness between 10 IRHD and 100 IRHD), TC45/SC2. ISO 48:1994.

18 Standard Practice for Determining Load Resistance of Glass in Buildings, ASTM International, (Beuth Verlag GmbH), 2004 July. ASTM E 1300-04.

19 Pankhardt K, Nehme SG, Experimental studies on carbon fibre reinforced white cement lightweight mortar and concrete elements, Proceedings The 3rd Central European congress on Concrete Engineering, Visegrád Hungary, 2007, pp. 269-274. 